\title{
Dizygotic Twin Infants: Controversial Case Study Series/Twin Research Reviews: Twin and Non-twin ICSI Conceptions; Emory University Twin Study; Labor in Multiple Pregnancy After Previous C-Section Delivery; Cell-Free DNA Fetal Fraction in Twin Pregnancies/ News Reports: Twin Survivor of Auschwitz; Twins Trading Places; Identical Twin Foals; Twins Born in Different Decades; Twins Ambulette Service
}

\author{
Nancy L. Segal \\ Department of Psychology, California State University, Fullerton, CA, USA
}

\begin{abstract}
This article describes a 1930s case study series involving dizygotic female twin infants. The twins' development was evaluated following periods of intentionally restricted practice and minimal social stimulation. In the opinion of the author of the current article, the study is very unsettling and unacceptable, despite the lack of institutional review boards at that time. This discussion is followed by twin research reviews of recent papers concerning twin and non-twin intracytoplasmic sperm injection conceptions, the Emory University Twin Study of cardiac and brain functions, labor trials in multiple pregnancies after previous C-section delivery and cell-free DNA fetal fraction in twin pregnancies. The article concludes with news items of a twin survivor of Auschwitz, a situation in which twins traded places, the rare birth of identical twin foals, the novel delivery of co-twins in different decades and the Twins Ambulette Service.
\end{abstract}

\section{Dizygotic Twin Infants: Controversial Case Study Series}

While researching material for a book in progress, I came across a very disturbing case series involving a pair of infant dizygotic (DZ) female twins. This work was published in highly reputable psychological journals between the years 1935 and 1938. Human subject regulations overseen by institutional review boards were not in place at that time as they are today. Nevertheless, it is difficult to understand how the researchers were content to carry out their procedures. I also wonder if their colleagues voiced concerns over the potential damage that the methods and goals of these experiments might have caused to the infants; perhaps they expressed their views privately, if not publicly. It seems clear that the manipulations that were performed disregarded the best interests of the babies as the search for answers to scientific questions took precedence.

The research was conducted by psychologist Wayne Dennis, from the Psychology Department at the University of Virginia,

\section{Author for correspondence: Nancy Segal, Email: nsegal@fullerton.edu}

Cite this article: Segal NL. (2020) Dizygotic Twin Infants: Controversial Case Study Series/Twin Research Reviews: Twin and Non-twin ICSI Conceptions; Emory University Twin Study; Labor in Multiple Pregnancy After Previous C-Section Delivery; Cell-Free DNA Fetal Fraction in Twin Pregnancies/News Reports: Twin Survivor of Auschwitz; Twins Trading Places; Identical Twin Foals; Twins Born in Different Decades; Twins Ambulette Service. Twin Research and Human Genetics 23: 190-193, https://doi.org/10.1017/thg.2020.50 in Charlottesville, and his research partner Mrs Dennis (Dennis, 1935a, 1935b, 1935c, 1938). The experiments focused on the effects of restricted practice and minimal stimulation on infants' reaching, sitting, standing, smiling, laterality of function and other behaviors. Given the comprehensiveness of the project, I will focus on the first series of studies that examined selected motor behaviors (Dennis, 1935a, 1935b, 1935c).

The participants were a pair of DZ female infant twins, identified by the Social Service Department of the university's hospital. The Dennis' original plan had been to study just one infant, but the twins were the first available participants. The researchers accepted the twins 'because they enable us to double the number of our subjects with considerably less than a doubling of cost and care' (Dennis, 1935a, p. 18). The twins were offered for study because their parents were unable to provide for them. Their mother was unemployed and had two children from a previous marriage, and their father was a taxi driver whose salary was limited. According to the investigators, the twins' mother knew that her two children would receive temporary care and understood the nature of the research in which they would be involved.

The twins, Del and Rey, were born on January 19, 1932, at the University of Virginia Hospital (Dennis, 1935a). They remained there for 8 days before being cared for by relatives. When the twins were 36 days old, they were brought to the Dennis home where a special research room had been created prior to their arrival. The study lasted a little over a year and ended on March 22, 1933. Aside 
from the highly questionable study procedures, the method by which the zygosity of the twins was determined was not provided. Of course, Dennis did not implement a co-twin control design, but certainty as to twin type might have affected interpretations of the findings. Scientific procedures for establishing zygosity were available in the 1930s, as described in detail by Newman et al. (1937). One procedure was the fetal-membrane method, considered to be of very limited value because monozygotic (MZ) twins can have separate chorions and placentae. The another procedure was the similarity method that compared resemblance in physical traits, such as hair color, facial features and dermatoglyphic characteristics; Newman et al. considered the similarity method to be far more informative than the inspection of fetal membranes. Both approaches were based on studies conducted in the 1920s and early 1930s.

All physical restrictions were introduced at the beginning of the experiment, but were removed once it was determined whether or not a particular response had been affected. No restriction lasted throughout the entire study period. The development of grasping was limited by not providing toys until the age of 11 months and by placing the hands tightly under a napkin while feeding. The development of sitting was restricted by keeping the babies on their backs. Their cribs were separated by a low screen; therefore, the babies could not see each other except when taken out of the crib or when they stood at later ages. During their first 6 months, the researchers refrained from smiling at, frowning at or talking to the twins and never played with them except during routine tests of social smiling at the age of 5 months; they did, however, talk to each other in the babies' presence. The nursery door remained closed. The babies could see trees and sky through the windows, but there were no pictures or decorations on the walls. The researchers surmised that these conditions were more extreme than those experienced by most American infants, although they did not have the data to know this for certain.

The twins' behaviors were compared with normative data available from other sources. The twins proved to be behind in their development of visually guided reaching and grasping, sitting alone and standing with support, relative to comparative norms. However, once training was introduced, reaching and standing were established, while sitting emerged more slowly. The researchers concluded that the lack of training was responsible for their findings. They discarded an alternative explanation based on the twins' possible muscle weakness. Specifically, they argued that the twins were continually active, albeit not in certain positions. In addition, early on the twins did not attempt to perform an activity that they were too weak to complete. Furthermore, reaching and grasping skills emerged quickly in an interval that would not have been long enough for muscle strength to develop had it been weak. The researchers also considered the possibility that the babies developed certain habits that were incompatible with the physical abilities under study. The twins did make some physical adjustments, but they were momentary. The researchers also discounted the idea that the twins suffered from organic impairments, given that practice brought about the intended response.

It is difficult to imagine how Dennis and his wife carried out these experiments and others in good conscience. In my view, they purposely manipulated the early development of two healthy infants to address a scientific question, with no regard for the twins' humanity. It seems likely that other infant populations, in which physical restraints are imposed in the event of bone fractures or surgeries, might have been available for study. The twins appeared to recover most skills once practice was introduced, but one wonders what might have happened had practice been available too late - serious damage might have been done. I question whether the twins' mother fully understood the situation in which she had placed her twins. I also wonder whether the researchers would have conducted, or agreed to allow others to conduct, similar experiments on their own children.

There is value in taking a look at this case study series. It urges us to think carefully about the wellbeing of the twins we study and the benefits twins can gain from participation. It also underlines how far twin research has advanced as a discipline for understanding human behavioral and physical development.

\section{Twin Research Reviews}

\section{Twin and Non-twin intracytoplasmic sperm injection Conceptions}

It has been estimated that couples using intracytoplasmic sperm injection (ICSI) to overcome infertility have a $30-35 \%$ chance of conceiving twins and a 5-10\% chance of conceiving triplets or more (Attain Fertility, 2019). Turkish researchers Uysal et al. (2020) compared the outcomes of non-twin ICSI pregnancies and twin pregnancies with spontaneous co-twin loss. They point out that multiple pregnancies pose well-known risks to newborns, including prematurity and low birth weight. They also note that cotwin loss occurs in approximately $30 \%$ of twin pregnancies diagnosed early in the first trimester.

Uysal et al. (2020) contrasted the outcomes of 33 ICSIconceived dichorionic twin pregnancies and 327 ICSI-conceived singleton pregnancies. Among the study group, co-twin loss occurred during the first trimester in 26 cases, during the second trimester in 4 cases and during the third trimester in 3 cases. There were two perinatal deaths in the control group. The mean birth weight and mean gestational age at delivery were significantly higher for the non-twins. As expected, the rate of preterm delivery and rate of neonatal intensive care unit (NICU) admission were significantly higher for the twins. However, differences in rates of preterm delivery and NICU admission were not observed between twins in the early loss group and the non-twins; this lack of difference may have reflected the very small twin sample, relative to the controls. Finally, loss of a dichorionic cotwin conceived by ICSI was linked to increased risk of preterm delivery. The risk was elevated when co-twin loss occurred late, compared to co-twin loss that occurred early.

\section{Emory University Twin Study}

Researchers at Emory University are studying MZ and DZ twin brothers to understand the relationship between cardiovascular characteristics (CCs) and cognitive performance (Jentz, 2019). So far, senior researcher Dr Viola Vaccarino has confirmed that better CCs are linked to better cognition across several domains. This association was similar in both $\mathrm{MZ}$ and DZ twin pairs, suggesting that environmental factors were responsible. The proposed environmental factors included the early family environment, socioeconomic status, education and parenting. A coauthor from the study, Dr Ambar Kulshreshtha, asserted that improving one's heart health is possible, leading to a healthier lifestyle and better cognitive performance. The original paper (not reviewed here) is published in the Journal of Alzheimer's Disease (Kulshreshtha et al., 2019). 


\section{Labor in Multiple Pregnancy After Previous C-Section Delivery}

Israeli researchers conducted a comprehensive literature review to determine the pregnancy outcomes in women carrying twins if they had had a previous cesarean (c-section) delivery (Kabiri et al., 2020). The number of women across citations was 8209, of which 5725 were intended for an elective repeat c-section delivery and 2484 were intended for attempted vaginal delivery. The rate of uterine rupture (as a measure or risk) was elevated when a trial of labor was allowed. However, uterine rupture did not differ between women pregnant with twins versus singletons. It was concluded that a planned vaginal delivery, rather than a planned repeat c-section, is a more favorable option for women pregnant with twins who have had a previous c-section delivery.

\section{Cell-Free DNA Fetal Fraction in Twin Pregnancies}

Noninvasive prenatal screening for genetic anomalies in twin pregnancies depends upon the amount of placentally derived cell-free DNA. This measure, known as the 'fetal fraction', is derived from the maternal plasma. A study conducted by Hedriana et al. (2020) compared the fetal fraction in 4416 twin and 121,446 singleton pregnancies. The twin pregnancies included $1454 \mathrm{MZ}$ pairs (31.51\%) and $3161 \mathrm{DZ}$ pairs (68.49\%). Zygosity was assessed by determining the number of genetically distinct individuals from the maternal plasma; two sources indicated MZ twins ( $M Z$ cotwins and mother), while three sources indicated DZ twins (DZ co-twins and mother). Mothers of DZ twins were significantly older and heavier than mothers of MZ twins and non-twins, consistent with previous studies (see Segal, 2017).

The mean fetal fraction was significantly lower for MZ twin pairs than for DZ twin pairs, but higher than for singletons. In addition, both the individual and mean fetal fractions were significantly higher for DZ twins than for singletons. It was also found that fetal fractions can be quite different for DZ co-twins. The Pearson correlation of .66 for DZ twins was not statistically significant. It was concluded that because the fetal fraction differs between $\mathrm{MZ}$ and $\mathrm{DZ}$ twins, the fetal fraction level required for effective genetic screening depends on zygosity, as does the prior risk used in screening algorithms.

\section{News Reports}

\section{Twin Survivor of Auschwitz}

Identical twin Mottie Alon, originally from Ujpest (now a suburb of Budapest, Hungary), was liberated from Auschwitz on January 27, 1945, by Russia's Red Army (Goldman \& Austin, 2020). He had been sent to Auschwitz at age 9, along with his identical twin brother, when his village was overtaken by the German army in 1944. The twins were part of the horrific experiments conducted on twins and individuals with genetic anomalies by the infamous physician Dr Josef Mengele (Segal, 1985). Alon claims that being a twin spared his life because he was a valued subject in these experiments.

Alon's given name was Andras Brichta, and that of his twin Yoel was Karoly. Both twins changed their names after moving to Israel when World War II ended. Alon was able to steal a sweater the day before the camp was liberated, a garment that kept him warm and helped him to survive. The year 2020 marks the 75 th anniversary of the liberation. The sweater will be on display at the World Holocaust Remembrance Center (Yad Vashem - Hand and Name), in Jerusalem, Israel.

\section{Twins Trading Places}

The story summarized here appeared in the news in 1994, but is worth examining in 2020 because it is such an extreme case of identical twin brothers trading places (Bray, 1994). Jailers discovered that an innocent man in Ventura County, California, was serving a half-year sentence for spouse abuse when, in fact, his identical twin brother was the guilty party. In jail was 43-year-old Donald Anderson who admitted that he had been in jail on three previous occasions, substituting for his identical twin brother Ronald. Donald had even completed his twin's military service. When asked to explain his decisions, Donald said that he did these acts because he loves his brother. The switch of places was discovered when Ronald was brought to jail because of an attack on his wife - however, the police were confused when they determined that someone of the same name was in jail for an earlier offense.

Donald and Ronald come from a family of 11 children and are originally from the inner-city area of Philadelphia, Pennsylvania. According to their father, the twins enjoy a closer relationship than do any other family members. Once it was discovered that Donald had taken Ronald's place in jail, the judge sentenced Ronald to 14 years of imprisonment. Again, Donald expressed his willingness to serve the time for his twin, claiming he is the one who should have received the sentence. It is unlikely he will be able to do so.

\section{Identical Twin Foals}

A horse named Destiny delivered identical twin foals in June 2018, an event with an estimated chance of 1:10,000. Eighteen months later, Destiny delivered a second set of nonidentical twins (Ferris, 2020). The delivery of a second pair of twins has an estimated chance of 1:1,000,000. It is rare for horses to deliver twins because two embryos typically abort within 6 weeks. However, all four twins are healthy. The twins, born at the Gassons Farm Stud near Exeter, England, are owned by Tania Mackee. The identical twins' names are GFS Shockwave and GFS Masta Black, but the most recent twins that are fraternal have not been named. Perhaps these twins and their mother can offer insight into the bases of human twinning, given that identical and fraternal twinning may not be independent in some families (Parisi et al., 1983). As evidence of that possibility, I described a set of naturally conceived quadruplets composed of two sets of identical twin males (Segal, 2007).

\section{Twins Born in Different Decades}

Male-female twins Joslyn and Jaxon Tello of Pendleton, Indiana, may be the first twins born in different decades (Fitz-Gibbon, 2020). They arrived just $30 \mathrm{~min}$ apart, but Joslyn exited the womb at 11:37 pm on Tuesday, December 31, 2019, while her twin brother Jaxon exited at 12:07 am on January 1, 2020. Their expected date of birth was February 19, making them approximately 6 weeks premature. Joslyn weighed 4 pounds, 11 ounces and Jaxon weighed 4 pounds, 4 ounces. First-born twins typically have a higher birth weight than second-born twins (Yokoyama et al., 2016).

\section{Twins Ambulette Service, Inc.}

I received information about the Twins Ambulette Service, Inc. from artist Gerald Marks who works with 3-D holography. Marks noticed the ambulette while walking in his lower Manhattan neighborhood and took the photograph displayed in Figure 1. The Brooklyn-based service was named 'Twins' because the owner is the father of an 
Fig. 1. Twins Ambulette Service. Photo credit: Gerald Marks.

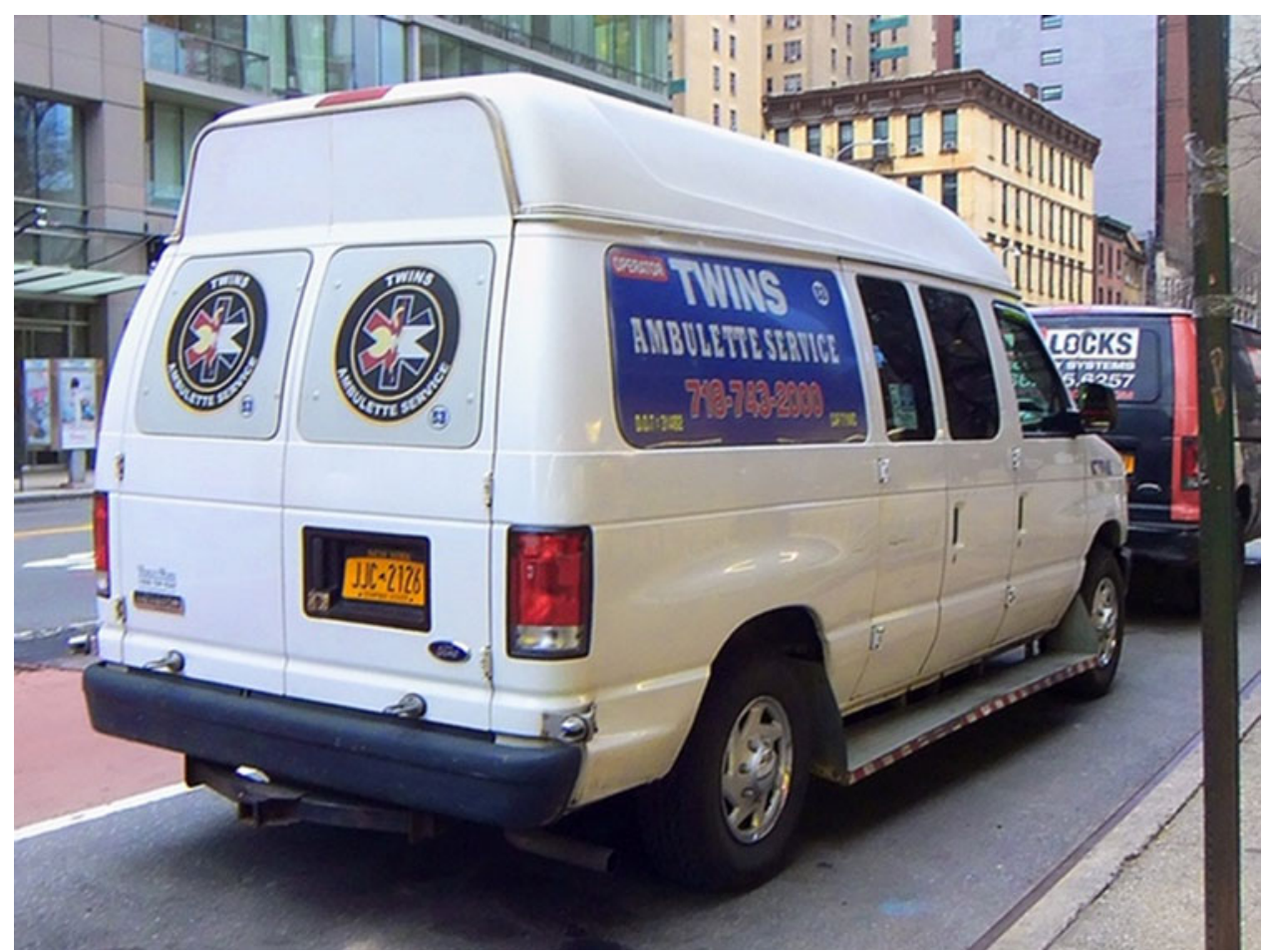

opposite-sex twin pair. Founded in 1993, the company offers local transportation to individuals with special needs, see Twins Ambulette Service (2020). An ambulette is a van or similar vehicle used to transport people to hospitals or other facilities in nonemergency situations (Merriam-Webster Dictionary, 2020).

\section{References}

Attain Fertility. (2019). ICSI benefits and risks. https://attainfertility.com/ understanding-fertility/treatment-options/icsi/icsi-benefits-and-risks/.

Bray, D. (1994, January 7). Brother's keeper: Man says he took twin's spot in jail, army. Los Angeles Times. https://www.latimes.com/archives/la-xpm-199401-07-me-9263-story.html.

Dennis, W. (1935a). The effect of restricted practice upon the reaching, sitting, and standing of two infants. The Pedagogical Seminary and Journal of Genetic Psychology, 47, 17-32.

Dennis, W. (1935b). An experimental test of two theories of social smiling in infants. The Journal of Social Psychology, 6, 214-223.

Dennis, W. (1935c). Laterality of function in early infancy under controlled developmental conditions. Child Development, 6, 242-252.

Dennis, W. (1938). Infant development under conditions of restricted practice and of minimum social stimulation: A preliminary report. The Pedagogical Seminary and Journal of Genetic Psychology, 53, 149-157.

Ferris, I. (2020, March 8). Horse that gave birth to identical twin foals defies 1million-1 odds after giving birth to another set just 18 months later. Daily Mail. https://www.dailymail.co.uk/news/article-8089425/Horse-gavebirth-identical-twins-defies-1 million-1-odds-giving-birth-second-set.html.

Fitz-Gibbon, J. (2020, January 5). Indiana twins born in different decades. New York Post. https://nypost.com/2020/01/05/indiana-twins-born-in-differentdecades/.

Goldman, P., \& Austin, H. (2020, January 25). Sweater stolen from Nazis educates people about Auschwitz death camp. NBC News. https://www. nbcnews.com/news/europe/sweater-stolen-nazis-educates-people-aboutauschwitz-death-camp-n1121951.

Hedriana, H., Martin, K., Saltzman, D., Billings, P., Demko, Z., \& Benn, P. (2020). Cell-free DNA fetal fraction in twin gestations in single-nucleotide polymorphism-based noninvasive prenatal screening. Prenatal Diagnosis, $40,179-184$

Jentz, M. (2019, October 21). Two of a kind: Emory study of twins shows what's good for the heart is good for the brain. Emory News Center. https://news. emory.edu/stories/2019/10/twins_study_heart_brain_study/index.html.

Kabiri, D., Masarwy, R., Schacter-Safrai, N., Masarwa, R., Raccah, B.H., Ezra, Y., \& Matok, I. (2020). Trial of labor after cesarean delivery in twin gestations: Systematic review and meta-analysis. Obstetric Anesthesia Digest, 40, 28-29.

Kulshreshtha, A., Goetz, M., Alonso, A., Shah, A. J., Bremner, J. D., Goldberg, J., \& Vaccarino, V. (2019). Association between cardiovascular health and cognitive performance: A twins study. Journal of Alzheimer's Disease, 71, 957-968.

Merriam-Webster Dictionary. (2020). Ambulette. https://www.merriamwebster.com/dictionary/ambulette.

Newman, H. H., Freeman, F. N., \& Holzinger, K. J. (1937). Twins: A study of heredity and environment. Chicago, IL: University of Chicago Press.

Parisi, P., Gatti, M., Prinzi, G., \& Caperna, G. (1983). Familial incidence of twinning. Nature, 304, 626-628.

Segal, N. L. (1985). Holocaust twins: Their special bond. Psychology Today, 19, 52-58.

Segal, N. L. (2007). Indivisible by two: Lives of extraordinary twins. Cambridge, MA: Harvard University Press.

Segal, N. L. (2017). Twin mythconceptions: False beliefs, fables, and facts about twins. New York, NY: Elsevier.

Twins Ambulette Service. (2020). Twins Ambulette Service Inc. Thryv. https:// www.superpages.com/bp/brooklyn-ny/twins-ambulette-service-inc-L00025 89180.htm.

Uysal, N. Ş., Gülümser, Ç., Bilgin Yanık, F. F., Önalan, G., \& Zeyneloğlu, H. B. (2020). Outcome of ICSI pregnancies with spontaneous loss of a co-twin compared with singleton ICSI pregnancies: Single center experience. Journal of Obstetrics and Gynaecology Research, 46, 445-450.

Yokoyama, Y., Jelenkovic, A., Sund, R., Sung, J., Hopper, J. L., Ooki, S., . . Willemsen, G. (2016). Twins' birth-order differences in height and body mass index from birth to old age: A pooled study of 26 twin cohorts participating in the CODATwins project. Twin Research and Human Genetics, 19, $112-124$. 